\title{
MORFOLOGI SERANGGA PADA TANAMAN KELAPA (Cocos nucifera L.) DI DESA TABALA JAYA KECAMATAN KARANG AGUNG ILIR KABUPATEN BANYUASIN
}

\author{
Denis Kartika ${ }^{1}$, Dian Mutiara ${ }^{2}$, Yunita Panca Putri ${ }^{3}$ \\ ${ }^{1,2,3}$ Program Studi Biologi, Fakultas MIPA, Universitas PGRI Palembang \\ *e.mail: deniskartika03@gmail.com
}

\begin{abstract}
Insect Morphology Research on Coconut (Cocos nucifera L.) in Tabala Jaya Village, Karang Agung Ilir District, Banyuasin Regency "was conducted in March to April 2020. The research objective was to determine the morphology of insects on coconut plants (Cocos nucifera L.) in Tabala Jaya Village. This study uses a purposive sampling method, namely three capture methods (insecting net, fitfall trap, light trap). Observation parameters included the type of head, mouth instrument, legs, antennae and wings. The results of the study obtained 135 insects from 5 orders, 9 families, 9 species. The types of insects found were Oryctes rhinoceros, Orthetrum sp., Neurothemis sp., Gryllus mitratus, Pheropsophus occipitalis, Oecophylla smaragdina, Xylocopa sp., Valanga sp., Junonia sp., Insects collected had different morphological types.
\end{abstract}

Keywords: Coconut Plants (Cocos nucifera L.), Insect, Morphological type

\begin{abstract}
ABSTRAK
Penelitian Morfologi Serangga Pada Tanaman Kelapa (Cocos nucifera L.) Di Desa Tabala Jaya Kecamatan Karang Agung Ilir Kabupaten Banyuasin" dilaksanakan pada Maret sampai April 2020. Tujuan penelitian untuk mengetahui morfologi serangga pada tanaman kelapa (Cocos nucifera L.) di Desa Tabala Jaya. Penelitian ini menggunakan metode purposive sampling yaitu dengan tiga metode penangkapan (insecting net, fitfall trap, light trap). Parameter pengamatan meliputi tipe kepala, alat mulut, tungkai, antena serta sayap. Hasil penelitian di peroleh 135 serangga dari 5 ordo, 9 familia, 9 spesies. Jenis serangga yang ditemukan yaitu Oryctes rhinoceros, Orthetrum sp., Neurothemis sp., Gryllus mitratus, Pheropsophus occipitalis, Oecophylla smaragdina, Xylocopa sp., Valanga sp., Junonia sp., serangga yang di kumpulkan memiliki tipe morfologi yang yang berbeda.
\end{abstract}

Kata kunci : Tanaman Kelapa (Cocos nucifera L.), Serangga, Tipe Morfologi 


\section{PENDAHULUAN}

Keanekaragaman hayati merupakan hal yang penting bagi kehidupan. Keanekaragaman hayati juga berperan sebagai indikator dari sistem ekologi dan sarana untuk mengetahui adanya perubahan spesies.

Keanekaragaman hayati juga mencakup kekayaan spesies dan kompleksitas ekosistem sehingga dapat mempengaruhi komunitas organisme, perkembangan dan stabilitas ekosistem (Rahayu, 2016). Penyebaran serangga dibatasi oleh faktor-faktor geologi dan ekologi yang sesuai, sehingga terjadi perbedaan keragaman jenis serangga. Perbedaan tersebut disebabkan karena perbedaan iklim, musim, ketinggian tempat dan jenis makanannya (Subekti, 2012).

Serangga merupakan bagian dari keanekaragaman hayati yang harus di jaga kelestariannya dari kepunahan maupun penurunan keanekaragaman jenisnya. Serangga memiliki nilai penting antara lain nilai ekologi, endemisme, konservasi, pendidikan, budaya, estetika dan ekonomi. Serangga bisa juga disebut hama yang dapat menyebabkan salah satu faktor penting yang harus diperhatikan dalam pembudidayaan kelapa, akibat serangan hama dapat menurunkan produksi dan kematian tanaman. Hama dapat menyerang tanaman kelapa, mulai dari pembibitan hingga tanaman menghasilkan (Fauzi $d k k .$, 2012).

Perkebunan kelapa di Sumatera Selatan memiliki areal yang luas hingga mencapai 65.308 hektar sebagian dari tanaman kelapa belum menghasilkan 5.477 hektar. Tanaman yang sudah menghasilkan 51.008 hektar, dan terdapat pula tanaman kelapa yang tua atau rusak 8.743 hektar dengan total produksi sebesar 59.788 ton. Daerah Kabupaten Banyuasin merupakan daerah yang memiliki tanaman kelapa sangat luas dengan areal 47.351 hektar dan produksi mencapai 44.334 ton (Direktorat Jenderal Perkebunan, 2014).

Pertanian utama di Indonesia perkebunan kelapa telah dikembangkan secara luas dan menjadi komoditas. Perkebunan kelapa tidak bisa lepas dari keberadaan serangga di areal perkebunan, keberadaan dan aktifitas serangga dipengaruhi oleh beberapa faktor seperti, udara, $\mathrm{pH}$, suhu, Kelemaban, intensitas cahaya. Faktor tersebut merupakan faktor yang paling berpengaruh terhadap perkembangan dan perilaku serangga dibandingkan faktor lainnya (Borror et al., 1992). Menurut Sunjaya (1994) dalam Putri (2011), faktor-faktor yang mempengaruhi kehidupan serangga adalah suhu, kelembaban udara, curah hujan, cahaya/penyinaran, dan angin. Selain itu faktor-faktor yang mempengaruhi kehidupan serangga yaitu parasitisme, predator, resistensi dan kompetisi antar serangga.

Serangga atau insekta juga hidup hampir pada setiap habitat teresterial sempurna dan lengkap terspesialisasi secara regional, dengan organ yang berfungsi dalam perombakan makanan dan penyerapan makanan. Seperti Arthropoda lainya, serangga mempunyai suatu sistem sirkulasi terbuka (Cambell et al., 2010).

Serangga memiliki keanekaragaman morfologi yang sangat tinggi sehingga serangga dapat hidup pada berbagai tipe habitat. Salah satu habitat serangga adalah pada lahan tanaman kelapa. Tanaman ini merupakan tanaman yang disukai sebagai habitat serangga baik serangga yang menguntungkan ataupun merugikan. Serangga. Salah satu serangga yang menguntungkan adalah belalang sembah sebagai predator pemangsa serangga yang merusak tanaman kelapa. Sedangkan serangga yang bersifat merugikan diantaranya kumbang, tungau, serta jenisjenis serangga lainnya ( Hosang, 2010). 


\section{BAHAN DAN METODE}

Penelitian dilaksanakan pada bulan Maret - April 2020. Pengambilan sampel serangga pada tanaman kelapa di Desa Tabala Jaya Kecamatan Karang Agung Ilir Kabupaten. Banyuasin. Adapun alat dan bahan yang digunakan adalah gelas plastik (tinggi $10 \mathrm{~cm}$ ), kertas label, insecting net, fitfall trap, light trap, alat tulis, baskom, pinset dan kamera. Sedangkan Bahan yang digunakan adalah air, larutan detergen, kapur barus, alkohol $70 \%$ dan spritus bening.

Metode yang digunakan berupa metode purposive sampling, pengambilan sampel yang dilakukan dengan memasang perangkap, insecting net, fitfall trap, dan light trap.

\section{HASIL DAN PEMBAHASAN}

Hasil penelitian yang telah dilakukan terhadap morfologi serangga pada tanaman kelapa (Cocos nucifera L.) di Desa Tabala Jaya Kecamatan Karang Agung Ilir Kabupaten Banyuasin, diperoleh serangga sebanyak 135 ekor serangga yang terdiri dari 5 ordo, 9 familia dan 9 spesies. Adapun jenis-jenis serangga yang ditemukan, disajikan pada Tabel 4.1 sebagai berikut:

Tabel 1. Jumlah Serangga yang ditemukan Pada Tanaman Kelapa (Cocos nucifera) DesaTabalaJayaKecamatanKarang Agung Ilir Kabupaten Banyuasin.

\begin{tabular}{|c|c|c|c|c|c|c|}
\hline \multirow[t]{2}{*}{ No } & \multirow[t]{2}{*}{ Ordo } & \multirow[t]{2}{*}{ Spesies } & \multirow[t]{2}{*}{ Nama Lokal } & \multicolumn{3}{|c|}{ Jumlah spesies dengan Metode penangkapan } \\
\hline & & & & Fit fall trap & insecting net & ligh trap \\
\hline 1 & Coleoptera & Orycthes rhinoceros & Kumbang Badak & 27 & - & 50 \\
\hline 2 & & $\begin{array}{l}\text { Pheropsophus } \\
\text { occipitalis }\end{array}$ & Kumbang tanah & 1 & - & 1 \\
\hline 3 & Odonata & Orthetrum sp. & $\begin{array}{l}\text { Capung } \\
\text { beradomen } \\
\text { bengkak }\end{array}$ & - & 11 & - \\
\hline 4 & & Neurothemis sp. & Capung peluncur & - & 9 & - \\
\hline 5 & Hymenoptera & $\begin{array}{l}\text { Oecophilla } \\
\text { smaragdina }\end{array}$ & Rang-rang & 20 & - & - \\
\hline 6 & & Xylocopa sp. & Lebah kayu & - & 4 & - \\
\hline 7 & Orthoptera & Gryllus mitratus & Jangkrik & 2 & - & - \\
\hline 8 & & Valanga sp. & Belalang kayu & 5 & - & - \\
\hline 9 & Lepidoptera & Junonia sp. & $\begin{array}{l}\text { Kupu-kupu } \\
\text { berkaki sikat }\end{array}$ & - & 4 & - \\
\hline & Total & & & 55 & 28 & 51 \\
\hline
\end{tabular}


Tabel 1 menunjukkan jumlah spesies yang diperoleh pada kebun kelapa (Cocos nucifera L.) di Desa Tabala Jaya spesies serangga terbanyak diperoleh dengan menggunakan metode fit fall trap sebesar 55 ekor, dengan metode light trap sebesar 51 ekor, dan dengan metode insecting net sebesar 28 ekor.

Serangga pada tanaman kelapa (Cocos nucifera L.) yang ditemukan paling banyak adalah kumbang badak karena ketersediaan inang dan tumpukan bahan organik dilapangan sebagai tempat perkembangbiakan dan makanan larva. Serangga ini juga berperan sebagai hama yang menyerang pucuk pohon dan pangkal daun muda yaitu jaringan mengandung cairan kaya akan gizi.

Orycthe rhinoceros serangga dari ordo Coleoptera merupakan serangga yang banyak ditemukan di lahan kebun kelapa (Cocos nucifera L.) di Desa Tabala Jaya dengan jumlah sebanyak 77 ekor. Serangga ini berperan penting dalam fungsi ekosistem (Schowalter, 2011). Serangga ini berperan sebagai predator. baik larva maupun dewasa hampir semua familia Scarabaeidae bersifat predator dan sedikit pemakan tanaman (Lilies, 1991). Banyaknya serangga predator ini disebabkan karena faktor lingkungan yang sesuai dengan kehidupan serangga ini. Faktor lingkungan tersebut yaitu faktor biotik dan abiotik. Faktor biotik bisa berupa ketersediannya jumlah makanan dan musuh alami pada lahan kebun kelapa (Cocos nucifera L.) di Desa Tabala Jaya dan selain itu faktor abiotik yang mempengaruhinya adalah faktor-kimia pada lahan kebun kelapa (Cocos nucifera L.) di Desa Tabala Jaya itu sendiri. Hal ini berdasarkan pernyataan Suin (2003) bahwa kelimpahan populasi suatu jenis serangga pada suatu daerah sangat bergantung dengan faktor lingkungan, yaitu lingkungan biotik dan abiotik. Faktor abiotik meliputi suhu, kelembaban, cahaya, curah hujan, dan angin. 
Tabel 2. Tipe-tipe Morfologi Serangga Pada Tanaman Kelapa (Cocos nucifera L.) di Desa Tabala Jaya Kecamatan Karang Agung Ilir Kecamatan Banyuasin.

\begin{tabular}{|c|c|c|c|c|c|c|}
\hline \multicolumn{7}{|c|}{$\begin{array}{c}\text { Tipe-tipe Morfologi } \\
\text { Serangga }\end{array}$} \\
\hline No & Spesies & Mulut & Kepala & Antena & Sayap & Tungkai \\
\hline 1 & $\begin{array}{l}\text { Orycthes } \\
\text { rhinoceros }\end{array}$ & $\begin{array}{l}\text { Menggigit- } \\
\text { mengunyah }\end{array}$ & Prognatus & Lamellate & Keras & Cursorial \\
\hline 2 & $\begin{array}{l}\text { Pheropsophus } \\
\text { occipitalis }\end{array}$ & $\begin{array}{l}\text { Menggigit- } \\
\text { mengunyah }\end{array}$ & Prognatus & Filiform & Keras & Cursorial \\
\hline 3 & $\begin{array}{l}\text { Neurothemis } \\
\text { sp. }\end{array}$ & $\begin{array}{l}\text { Menggigit- } \\
\text { mengunyah }\end{array}$ & Hypognatus & Setaceus & Membentang & Cursorial \\
\hline 4 & Orthetrum sp. & $\begin{array}{l}\text { Menggigit- } \\
\text { mengunyah }\end{array}$ & Hypognatus & Setaceus & Membentang & Cursorial \\
\hline 5 & Xylocopa sp. & $\begin{array}{l}\text { Menusuk- } \\
\text { menghisap }\end{array}$ & Prognathous & Genikulate & Bermembran & Natatorial \\
\hline 6 & $\begin{array}{l}\text { Oecophylla } \\
\text { smaragdina }\end{array}$ & $\begin{array}{l}\text { Menggigit- } \\
\text { menghisap }\end{array}$ & Hypognatus & Setaceus & $\begin{array}{l}\text { Tidak } \\
\text { Memiliki } \\
\text { Sayap }\end{array}$ & Natatorial \\
\hline 7 & $\begin{array}{l}\text { Gryllus } \\
\text { mitratus }\end{array}$ & $\begin{array}{l}\text { Menggigit- } \\
\text { mengunyah }\end{array}$ & Prognatus & Setaceus & Lurus & Saltatorial \\
\hline 8 & Valanga sp. & $\begin{array}{l}\text { Menggigit- } \\
\text { mengunyah }\end{array}$ & Hypognatus & Filiform & Lurus & Saltatorial \\
\hline 9 & Junonia sp. & Menghisap & Prognatus & Filifrom & Sisik & Natatorial \\
\hline
\end{tabular}

Berdasarkan hasil penelitian dan pengamatan yang dilakukan terhadap morfologi serangga yang ditemukan pada kebun kelapa (Cocos nucifera L.) Desa Tabala Jaya kecamatan Karang Agung Ilir di dapatkan 9 spesies. Berikut deskripsi dari tiap-tiap spesies yang didapatkan.

\section{Spesies 1. Kumbang badak (Oryctes rhinoceros)}
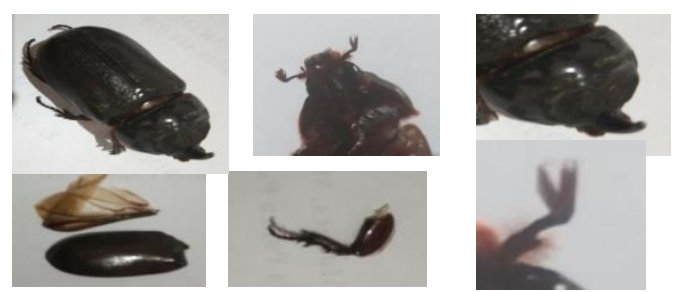
a. Klasifikasi

Menurut Borror et al., 1992 kumbang badak diklasifikasikan sebagai berikut:

$\begin{array}{ll}\text { Kingdom } & \text { : Animalia } \\ \text { Filum } & \text { : Arthropoda } \\ \text { Kelas } & \text { : Insecta } \\ \text { Ordo } & \text { : Coleoptera } \\ \text { Famili } & \text { : Scarabaeidae } \\ \text { Genus } & \text { : Oryctes } \\ \text { Spesies } & \text { : Oryctes rhinoceros }\end{array}$

Spesies 2. Capung berabdomen bengkak (Orthetrum sp.)
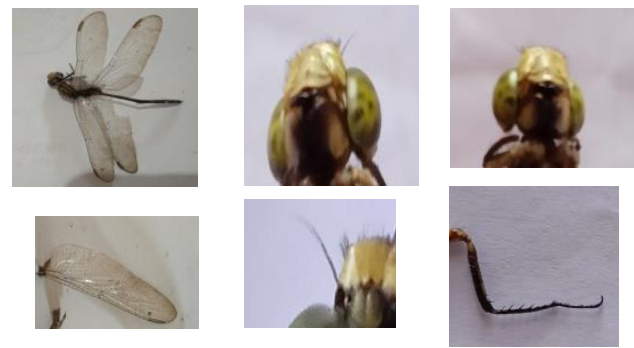

a. Klasifikasi

Menurut Borror et al., 1992 capung diklasifikasikan sebagai berikut:

Kingdom : Animalia

Filum : Arthropoda

Kelas : Insecta

Ordo : Odonata

Famali : Ghomphidae

Genus : Orthetrum

Spesies : Orthetrum sp.

\section{Spesies 3.Capung peluncur} (Neurothemis sp.)
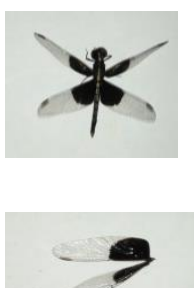
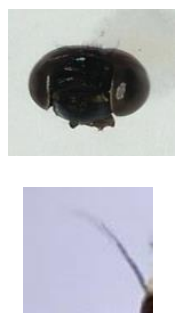

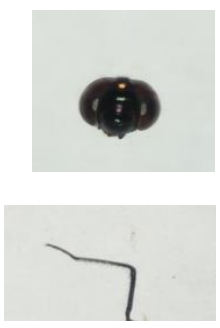

a. Klasifikasi

Menurut Borror et al., 1992 capung peluncur diklasifikasikan sebagai berikut:

Kingdom : Animalia

Filum : Arthropoda

Kelas : Insecta

Ordo : Odonata

Famili : Libellulidae

Genus : Neurothemis

Spesies : Neurothemis sp.

\section{Spesies 4. Jangkrik (Gryllus mitratus)}
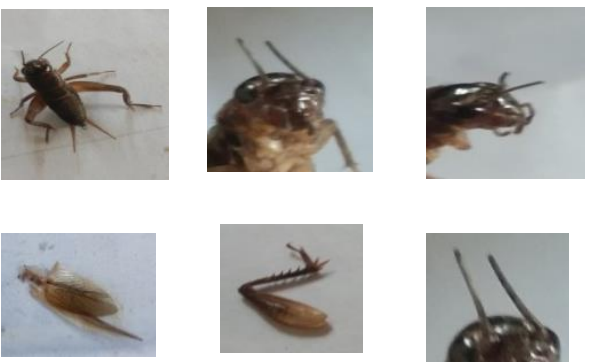

a. Klasifikasi

Menurut Borror et al., 1992 jangkrik diklasifikasikan sebagai berikut:
Kingdom : Animalia
Filum : Arthropoda
Kelas : Insecta
Ordo : Orthoptera
Familia : Gryllidae
Genus : Gryllids
Spesies : Gryllus mitratus

Spesies 5. Kumbang tanah

(Pheropsophus occipitalis)
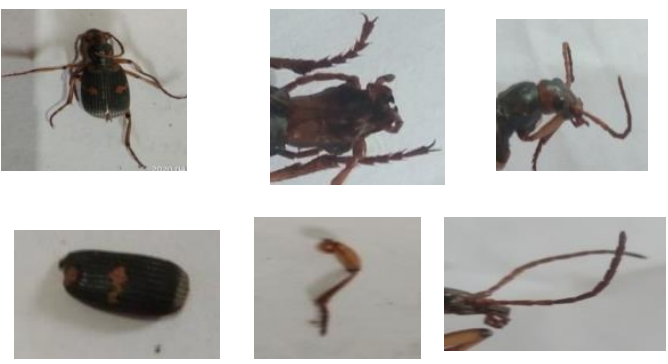

a. Klasifikasi

Menurut Borror et al., 1992 kumbang tanah diklasifikasikan sebagai berikut:
Kingdom
: Animalia
Filum
: Arthropoda 


$\begin{array}{ll}\text { Kelas } & \text { : Insecta } \\ \text { Ordo } & \text { : Coleoptera } \\ \text { Famili } & \text { : Carabidae } \\ \text { Genus } & \text { : Pheropsophus } \\ \text { Spesies } & \text { : Pheropsophus sp. } \\ \text { Spesies 6. Rang-rang (Oecophilla } & \\ \text { smaragdina) } & \end{array}$
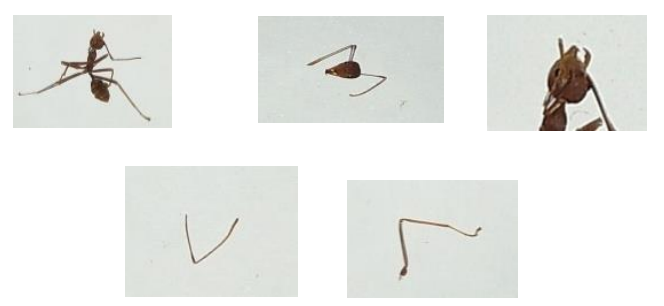

b. Klasifikasi

Menurut Borror et al., 1992 rang-rang dikelasifikasikan sebagai berikut:

$\begin{array}{ll}\text { Kingdom } & \text { : Animalia } \\ \text { Filum } & \text { :Arthropoda } \\ \text { Kelas } & \text { :Insecta } \\ \text { Ordo } & \text { :Hymenoptera } \\ \text { Famili } & \text { :Formicidae } \\ \text { Genus } & \text { :Oecophilla } \\ \text { Spesies } & \text { :Oecophilla smaragdina }\end{array}$

\section{Spesies 7. Lebah kayu (Xylocopa sp.)}
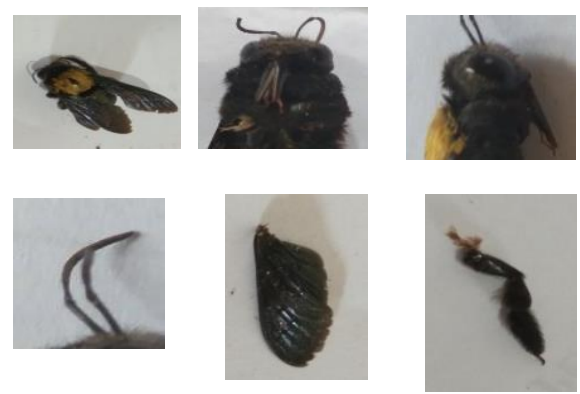

a. Klasifikasi

Menurut Borror et al., 1992 tawon diklasifikasikan sebagai berikut:

$\begin{array}{ll}\text { Kingdom } & \text { : Animalia } \\ \text { Filum } & \text { : Arthropoda } \\ \text { Kelas } & : \text { Insect } \\ \text { Ordo } & : \text { Hymenoptera } \\ \text { Family } & : \text { Apidae } \\ \text { Genus } & : \text { Xylocopa }\end{array}$

Spesies $\quad$ : Xylocopa $\mathrm{sp}$.

\section{Spesies 8. Belalang kayu (Valanga sp.)}
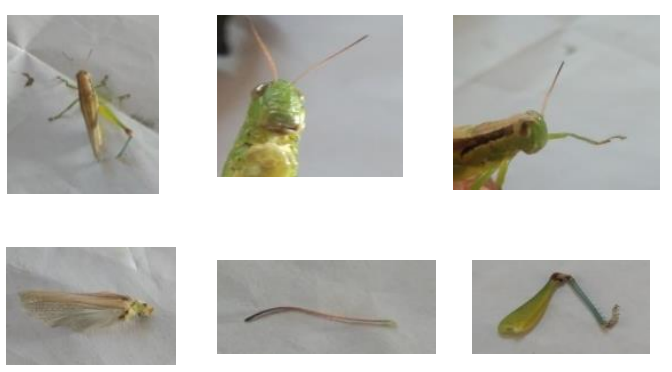

b. Klasifikasi

Menurut Borror et al., 1992 belalang diklasifikasikan sebagai berikut:

$\begin{array}{ll}\text { Kingdom } & \text { : Animalia } \\ \text { Filum } & \text { : Arthropoda } \\ \text { Kelas } & \text { : Insecta } \\ \text { Ordo } & \text { : Orthoptera } \\ \text { Family } & \text { : Acrididae } \\ \text { Genus } & \text { : Valanga } \\ \text { Spesies } & \text { : Valanga } \text { sp. }\end{array}$

Spesies 9. Kupu-kupu berkaki sikat (Junonia sp.)
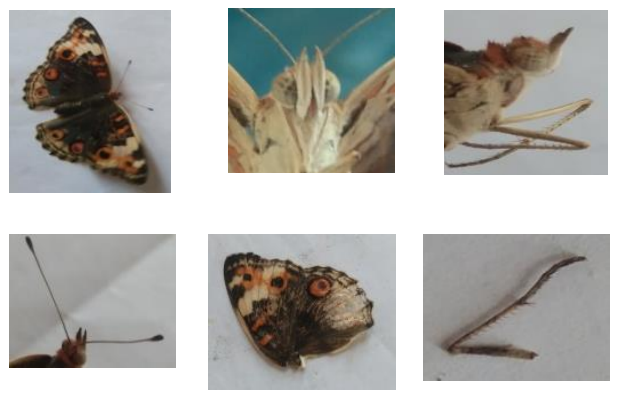

a. Klasifikasi

Menurut Boror et al., 1992 kupu-kupu di klasifikasikan sebagai berikut:

$\begin{array}{ll}\text { Kingdom } & \text { : Animalia } \\ \text { Filum } & \text { : Arthropoda } \\ \text { Kelas } & \text { : Insekta } \\ \text { Ordo } & \text { : Lepidoptera } \\ \text { Family } & \text { : Nyimpaliday } \\ \text { Genus } & \text { : Junonia } \\ \text { Spesies } & \text { : Junonia sp. }\end{array}$




\section{KESIMPULAN}

1. Serangga yang ditemukan adalah kumbang badak (Orycthe rhinoceros), kumbang tanah (Pheropsophus occipitalis), capung beradomen bengkak (Orthetrum sp.), rang-rang (Oecophilla smaragdina), lebah kayu (Xylocopa sp.), capung peluncur (Neurothemis sp.), jangkrik (Gryllus mitratus), belalang kayu (Valanga sp.), kupu-kupu berkaki sikat (Junonia sp.).

2. Tipe morfologi serangga pada kepala terdapat tipe prognatus, hypognatus. Antena terdapat tipe lamellate, filiform, setaceus dan geniculate. Tipe mulut terdapat tipe menggigit-mengunyah, menggigit-menghisap, menusukmenghisap, menghisap. Sayap terdapat 5 tipe membentang, keras, bermembran, lurus, sisik. Tungkai 2 tipe cursorial dan natatorial.

\section{DAFTAR PUSTAKA}

Borror, D.J., Triplenhorn, A. dan Jonson, N.F. 1992. Penggenalan Pelajaran serangga. Edisi Enam. (Terjemahan). Yogyakarta: Gadjah Mada Universitas Press.

Campbell, N. A. dan J. B. Reece. 2010. 3. Biologi, Edisi Kedelapan Jilid 3. Terjemahan: Damaring Tyas Wulandari. Erlangga: Jakarta.
Departemen Pertanian, Direktorat Jenderal Perkebunan. 2015. Statistik perkebunan Indonesia 2014-2015: Kelapa (Coconut). Jakarta: Direktorat Jenderal Perkebunan.

Fauzi, Y, Widyastuti Y. E, Wibawa I. S, paeru R. H. 2012. Kelapa Sawit. Penebar Swadaya : Jakarta. Hal 236.

Hosang, MLA., 2010. Serangan Hama Bunga Kelapa. (Lepidoptera : Pyralidae) pada Tanaman Kelapa Genjah Salak di Kebun Percobaan Kima Atas. Buletin Palma. 39: 172 180.

Putri, Y. P. 2011. Identifikasi SeranggaSerangga pada Tanaman Cabai Merah (Capsicum annum L.) di Desa Santosa Kecamatan Sukarami Kota Palembang. Jurnal Sainmatika. 8(1):43-48.

Rahayu. 2016. Keanekaragaman Hayati. Airlangga: Jakarta.

Subekti, N. 2012. Keanekaragaman Jenis Serangga Di Kawasan Hutan Tinjomoyo Semarang Jawa Tengah. Vol 01. Halaman 21-31 